\title{
Systemic Professional Learning through Collaborative Inquiry: Examining Teachers' Perspectives
}

Christopher DeLuca, Benjamin Bolden, \& Jessica Chan

a'Faculty of Education, Queen's University, Kingston, Canada

Full Citation:

Christopher DeLuca, Benjamin Bolden, \& Jessica Chan. (2017). Systemic professional learning through collaborative inquiry: Examining teachers' perspectives. Teaching and Teacher Education, 67, 67-78.

https://doi.org/10.1016/j.tate.2017.05.014
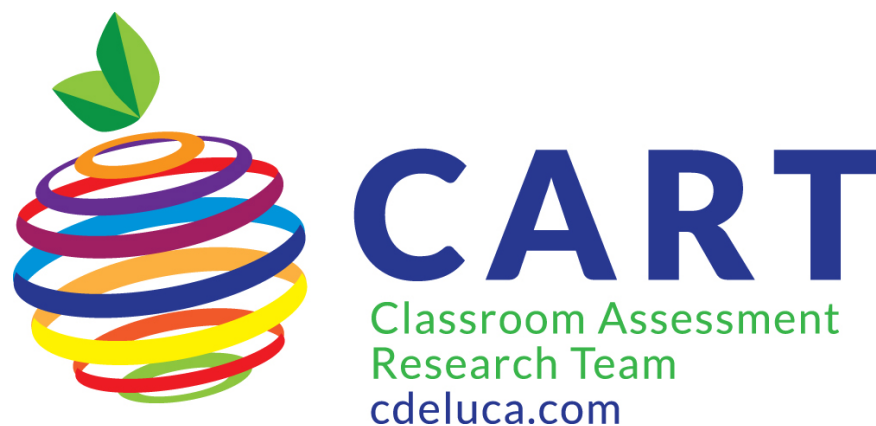

Classroom Assessment

Contact:

Research Team

cdeluca.com

Christopher DeLuca

cdeluca@queensu.ca

@ChrisDeLuca20 


\begin{abstract}
Collaborative Inquiry (CI) engages teachers to jointly inquire into a shared problem of practice. The majority of CI research presents qualitative case studies of individual collaborative inquires; few studies directly examine teachers' responses to CI through a large-scale study across an entire system of education. To examine teachers' perspectives on the impact and functionality of CI as professional learning, we surveyed 292 elementary teachers across 15 school districts and conducted 6 focus groups with teachers who had been involved in CI. We report the factors that enhance and inhibit teacher experiences of CI and significant outcomes from a teacher perspective.
\end{abstract}

Keywords: collaborative inquiry, professional learning, professional development, in-service teacher education, professional learning community 
Recently, in-service teacher learning has evolved from an emphasis on individual reflective practice to collaborative systematic inquiry (Borko, 2004; Opfer \& Pedder, 2011). Current professional development (PD) promotes context-embedded and data-driven learning focused directly on teachers' identified problems of practice. In particular, Collaborative Inquiry (CI) has become a dominant framework for engaging teachers in professional learning throughout North America and elsewhere (Butler \& Schnellert, 2012; Comber, 2013; Timperley, \& Lee, 2008). CI entails a sequenced co-learning process in which educators investigate their professional practice taking into consideration classroom-based data, students' responses to instruction, existing literature, teachers' shared experiences, and teachers' learning goals (Webster-Wright, 2009). Integrating these considerations into purposeful and structured professional learning provokes teacher reflection leading to new understandings and responsive classroom actions (Lee, 2009). Ultimately, CI engages teachers as learners within their own teaching contexts with the aim of transforming teachers' conceptions of professional learning and promoting enhanced pedagogical effectiveness (Elmore, 2004; Hannay, Wideman, \& Seller, 2010).

The reported impact of collaborative learning cultures on both school improvement and student achievement has been consistently touted in the extant literature (Huffman \& Kalnin, 2003; Vescio, Ross, \& Adams, 2008) suggesting it is a key feature for educator growth and development (Cordingley, Bell, Evans, \& Firth, 2005). However, few studies have directly examined teachers' responses to CI across an entire system of education. The majority of CI research presents qualitative case studies that examine the learning intentions, actions, and results of a small number of teachers (e.g., Butler \& Schnellert, 2012; Clausen, Aquino, \& Wideman, 2009; Ermeling, 2010; Slavit, Nelson, \& Deuel, 2013). These studies provide useful 
descriptive evidence on how to engage in CI while identifying potential challenges and enabling support structures, but are limited in their ability to address the systematic impact or large-scale capacity of CI to influence teacher learning across regions (DeLuca et al., 2015; Vescio et al., 2008).

The absence of systemic data on CI is concerning, given its growing popularity for teacher professional learning (Butler \& Schnellert, 2012; Webster-Wright, 2009). There is an urgent need to explore its perceived effectiveness across a larger sample. In this study, we surveyed 292 elementary teachers from 15 school districts and conducted six focus groups with teachers who had been involved in CI professional learning in six districts. Our primary purpose was to examine teachers' perspectives towards the impact and functionality of CI as professional learning guided by the following questions:

1. What factors enhance teachers' experiences of CI?

2. What factors inhibit teachers' experiences of CI?

3. What do teachers perceive as significant outcomes of CI?

\section{Conceptualizing Collaborative Teacher Inquiry}

Within a CI model of professional learning educators participate as co-learners in an authentic community of practice, jointly inquiring into a shared problem of practice (Schnellert, Butler, \& Higginson, 2008). Through a cycle of inquiry, teachers work together and alongside principals, school district leaders, and external partners to investigate their pedagogy with the ultimate goal of improving student learning and school experiences (Donohoo, 2013). Researchers and PD planners have characterized the steps of the CI cycle differently; however, most characterizations involve an iterative process of (a) identifying an inquiry focus; (b) determining what knowledge and skills teachers need; (c) deepening professional knowledge and 
skills; (d) implementing changes in practice; (e) collecting and co-analyzing student data related to the inquiry focus; and (f) reflecting on learning and subsequently refining the inquiry focus. The result of this cycle of inquiry is a learning experience situated within the teacher's own professional context that both promotes teachers' pedagogical development and drives participation in a professional learning community (Lee, 2009; Ontario Literacy and Numeracy Secretariat, OLNS, 2010).

CI has been primarily conceptualized in the literature from a socio-constructivist perspective in which individual and shared experiences contribute to contextualized meaning making (e.g., Butler \& Schnellert, 2012; Robinson, 2010). CI frameworks emphasize dialogue as central for co-constructing knowledge and responding to inquiries. Nelson, Slavit, Perkins, and Hathorn (2008) state, CI involves “a stance of ‘knowledge negotiation’ (Nelson, 2005) among group members. Employing dialogue grounded in shared experiences and a shared focus" (p. 1272). Further, as Horn and Little (2009) noticed in their study of two professional learning groups focused on problems of practice, differences in the generativity of the group resulted from “each group's collective orientation and its contextual resources and constraints" (p. 211). Specifically, the more successful group maintained a commitment to conversational routines and to resourcing their 'problem of practice.' In addition to socio-constructivist theories, CI has been linked to professional learning, cognition, and self-regulation theories (Butler \& Schnellert, 2012; Cunningham, 2011; Nelson \& Slavit, 2008). Using a self-regulatory framework for CI further acknowledges teacher's individual capacity to establish learning goals, self-assess, monitor learning progress, and reflect on learning to stimulate new inquiries (Winne \& Hadwin, 1998; Zimmerman \& Schunk, 2001). 
Framing CI from socio-constructivist and self-regulatory frameworks serves to address learning processes at individual levels; however, in this paper, we also seek to understand CI from a systemic perspective (i.e., initiated by governments) (Borko, 2004; Schnellert et al., 2008). Systemically, CI falls within a neoliberal construction of 'networked learning,' in which there is a focus on mobility of practices through tropes of 'connectivity' and 'collaboration' (Ball, 2012). CI as networked learning provides "venues for collaborative solutions and mobilized innovations" related to pedagogy and learning (Ball, 2012, pp. 5-6). Within the international movement toward a neoliberal approach (Lakes \& Carter, 2011; Ross \& Gibson, 2007), Ball recognizes that governance structures and institutionalized power relations move from a directly hierarchical position (i.e., vertical hegemony) to situated across agents within networks. While mandates for CI stem from ministries of education, governance of CI is shared across system levels, with power operating horizontally and vertically. Within CI, this neoliberal governance framework presents a tension between the needs of the system in form and content of PD and autonomy in teacher learning (DeLuca et al., 2015). This tension further problematizes the role of contextualized learning in CI, as teachers are simultaneously directed to select individualized inquiry areas while maintaining alignment to system goals that generate 'best practices.' As a result, a neoliberal framing of CI as networked learning involves a continuous stance of negotiation between individual, group, and system dynamics, ultimately recognizing “the multicausal and multidimensional nature of teacher learning" (Opher \& Pedder, 2011, p. 394).

\section{Collaborative Inquiry Literature}

CI naturally follows from previous practitioner-driven models of inquiry, namely critical reflection, action research, and professional learning communities (Elmore, 2000; Opfer \& 
Pedder, 2011). Groundwater-Smith and Mockler (2007) recognize that the aim of these professional learning approaches is to help practitioners understand practical problems, locate problems within a wider discourse, and explore the conditions that support solutions. In considering criteria for quality in practitioner research models (i.e. CI), Groundwater-Smith and Mockler argue that research must address ethical and emancipatory dimensions; in particular, quality practitioner inquiry should address problems of practice through practical changes, and such changes should be shared with a broader professional community.

Within this understanding of practitioner-driven inquiry, existing literature on CI falls into two domains: (a) practitioner professional resources aimed at supporting CI as an enacted professional learning model (e.g., Cunningham, 2000; David, 2009; Donohoo, 2013; Little, 2002); and (b) case studies on schools and teachers using CI (e.g., Butler \& Schnellert, 2012; Ermeling, 2010; Nelson et al., 2012).

In a recent scoping review on CI literature, DeLuca et al., (2015) identified empirically substantiated challenges and benefits associated with CI as a professional learning model. For example, CI is not effective when teachers do not 'buy-in' to a collaborative culture characterized by sharing, pedagogical implementation, collaborative analysis, and open reflection (DeLuca et al., 2015). For buy-in to occur, teachers need to believe that they will be fully supported in their CI work (Nelson \& Slavit, 2008). Support factors include release time, leadership, guidance, data literacy support, and a culture of collaboration within the school (DeLuca et al., 2015).

When challenges are mitigated through supports, there appears initial evidence of teacher and school benefits of CI. For teachers, benefits include: (a) development of content and pedagogical knowledge and skills to enhance teaching and student learning, (b) development of a 
learning community, and (c) opportunities for teacher leadership (Galligan, 2011; Nelson, 2009;

Robinson, 2010). The impact of CI for schools include: (a) greater curriculum alignment within and across grade levels, (b) introduction of new ideas that can be incorporated into school improvement goals, (c) PD targeted to teachers' needs, (d) shifts to collaborative school cultures that can support inquiry into student success, and (e) access to universities as sources of knowledge and information (Forey, Firkins, \& Sengupta, 2012; Nelson, 2009).

Existing research makes significant strides in describing the intentions and structures for CI, with some emerging studies examining teachers' responses to this professional learning model (e.g., Galligan, 2011; Nelson, 2009; Robinson, 2010). Our study builds on this work by examining large-scale data focused on Ontario teachers' perspectives towards the impact and functionality of CI as a model for teacher learning.

\section{Contextualizing Our Study}

The province of Ontario provides an ideal context for collecting large-scale data on teachers' responses to CI. The Ontario Ministry of Education has been committed to promoting educator learning through CI for nearly a decade and has steadily maintained its goal of “improved student achievement by cultivating teachers' professional learning communities" (OLNS, 2007, p. 1). As recognized by Ball (2012) and Borko (2004) in other international contexts, such a focus represents a move in professional learning to establish coherent learning goals for educators across school districts within a system. At the elementary level, the Ontario Ministry of Education has formally promoted CI throughout the province via its endorsement of named and funded projects as part of 'CI-Elementary,' seeking to build CI capacity within teachers, schools and school boards, to establish a systemic learning culture across the province, and ultimately to improve student academic achievement. 


\section{Our Conceptual Framework for Collaborative Inquiry}

Given the contextualized nature of CI, we draw specifically on the framework provided by the OLNS (2010) as a conceptual foundation for our study. While this framework is based in documentation from the Ontario context, it also characterizes CI processes evident in other educational jurisdictions in Canada and elsewhere (e.g., Ermeling, 2010; Kennedy, Deuel, Nelson, \& Slavit, 2011; Robinson, 2010). Specifically, our CI framework articulates seven characteristics of teacher inquiry that work together to create new understandings and actions in relation to teachers' practical pedagogical problems. These characteristics are:

1. Relevance: Student learning guides inquiry.

2. Collaborative: Teacher inquiry is a shared process.

3. Reflective: Actions are informed by reflection.

4. Iterative: Progressive understanding grows from cycles of inquiry.

5. Reasoned: Analysis drives deep learning.

6. Adaptive: Inquiry shapes practice and practice shapes inquiry.

7. Reciprocal: Theory and practice connect dynamically.

Combined, these characteristics work across the CI cycle to support teachers as they collectively inquire into a shared problem of practice (OLNS, 2010).

\section{Method}

This research used multiple methods - survey and focus groups. The survey was distributed to elementary teachers representing 15 school districts across the province of Ontario. Teachers from six of these districts also participated in focus group interviews. School districts were selected based on their explicit commitment to CI as a professional learning model (i.e., the Ontario Ministry of Education had implemented and promoted CI in various forms in each of the 
selected school districts). Ethical clearance was obtained from our university ethics board and participating school districts. All participants formally consented to participation in this study.

\subsection{Survey}

The purpose of the 66-item survey was to provide a broad measure of teachers' experiences with CI and their perspectives towards the impact and functionality of CI as professional learning. Survey items also ascertained teachers' professional learning preferences and demographic information. The survey was developed by a team of researchers in close consultation with practicing teachers and officials from the OLNS. The research team used literature on CI to construct questions relevant to the study's purpose while teachers and members of the OLNS attended to the language and form of the survey. Feedback from a pilottest phase with ten elementary teachers using a think-aloud protocol was integrated before fullscale dissemination (Patton, 2015).

\subsection{Participants}

Elementary teachers were administered the surveys electronically via school board supervisory officers (i.e., school district consultants and PD leaders) in 15 school districts representing geographic diversity. In total, 292 elementary teachers completed the survey. Of respondents, $83 \%$ were female and $88 \%$ reported that they had been involved in Ministrysupported formalized CI-Elementary initiatives in Ontario schools (the remainder engaged in ad hoc and informal CI activities). Specifically, teachers were involved with a cycle of CI including identifying professional learning goals rooted in a 'problem of practice' and co-learning about the problem of practice by examining student level data and engaging in PD activities. Respondents also differed in their teaching divisions, with $40 \%$ teaching in the primary division (Grade K-3), 30\% teaching in the junior division (Grades 4-6), and 23\% teaching in the 
intermediate division (Grades $7-8$ ). A further $20 \%$ of the teachers indicated that their teaching included other responsibilities (e.g., library, Special Education, English Language Learners). Across the data set there were respondents from each of the 15 school boards.

Ontario's public schools maintain a consistent governance structure with schools belonging to school boards. School boards report to and receive funding and mandates directly from the Ontario Ministry of Education. The schools follow a common provincial curriculum across subject areas and engage in a provincial large-scale assessment program involving testing in literacy and/or numeracy in Grades 3, 6, 9, and 10. The geographic and demographic composition of schools throughout Ontario is diverse, from rural settings with fairly homogenous student and teacher populations to urban and suburban settings with high levels of linguistic and cultural diversity.

\subsection{Quantitative Data Analyses}

Data collected from the survey were analyzed using descriptive statistics and factor analysis. Descriptive statistics provided contextual information on teachers and general response trends. Factor analytic techniques were used to investigate the dimensionality of the survey capturing teachers' experiences of CI and their perspectives towards the impact and functionality of CI. Specifically, we examined four sets of thematically grouped items within the larger survey: teachers' CI activities, factors that enhanced CI, factors that inhibited CI learning, and perceived significant outcomes of CI.

Exploratory factor analysis (EFA) determines the underlying latent factors based on a common factor model that account for the relationships between measured variables (Fabrigar, Wegener, MacCallum, \& Strahan, 1999). Assumptions of EFA were met for sample size, level of measurement, and correlations between variables. Univariate normality estimates for the 
majority of measured variables were within normal range, in which skewness values fell below $<2$ and kurtosis below $<7$ (Fabrigar \& Wegener, 2012; West, Finch, \& Curran, 1995). Mardia's multivariate normality coefficients (1970) for skewness were within normal range, whereas, kurtosis values were significantly non-normal in each group of items. To address these characteristics of our data, we used polychoric correlations, and principal axis factoring for EFA analyses, which are methods recommended for ordinal data and data that are multivariate nonnormal (Baglin, 2014; Fabrigar et al., 1999; Garrido, Abad, \& Ponsoda, 2013; Holgado-Tello, Chaćon-Moscoso, Barbero-Garcia, \& Vila-Abad, 2008).

Initial factor extraction involved the examination of Horn's (1965) parallel analysis and Velicer's (1976) minimal average partial (MAP) test computed through the EFA program FACTOR (Lorenzo-Seva \& Ferrando, 2006) to identify the number of factors to retain. The current analyses are exploratory without an a priori theoretical framework, and the results of the two objective tests for factors to retain inform the number of factors for rotated factor solutions. For rotation methods, we chose oblique methods, which is a more general approach that permits correlations among common factors appropriate for our groups of items (Costello \& Osborne, 2005). We applied the oblique rotation of direct oblimin, which restricts the degree of correlation between measures from 0 (high correlation) to negative values (low correlations) (Thompson, 2004).

\subsection{Focus Groups}

Our team collected qualitative data from 63 elementary teachers via six school-based focus groups representing six districts. Schools were selected on the recommendation of school district supervisory officers with teachers recommended by school principals. This selection strategy enabled a purposeful sample of elementary teachers who had participated in CI. 
Questions focused on teachers' experiences of CI including (a) factors that enhanced CI learning, (b) factors that inhibited its effectiveness, and (c) perceived outcomes from CI learning. Focus groups lasted approximately one hour and were audio recorded and transcribed verbatim.

\subsection{Qualitative Data Analyses}

Data collected from all focus groups were collapsed for analysis purposes. Our inductive thematic analysis was guided by our overarching research questions (Patton, 2015). We inductively generated an emergent code list from the data and systematically applied the codes to the entire data set with an inter-rater reliability of $88 \%$ across three raters. Where quotations were mis-coded, researchers discussed quotations and either reached consensus or double-coded the datum. Based on coded data, thematic categories were generated by analyzing code cooccurrence and logical coupling (Patton, 2015).

\section{Findings}

Survey and focus group data were analyzed in relation to the three research questions: (a) what factors enhance teachers' experiences of CI, (b) what factors inhibit teachers' experiences of CI, and (c) what are the perceived significant outcomes of CI from teachers' perspectives. It should be noted that findings from qualitative and quantitative data sources work together to characterize the CI processes and experiences of teachers. In order to situate the findings, we first present baseline data on teachers' CI activities.

\subsection{Teachers' CI Activities}

While all teachers in this study experienced CI in some form we recognize that not all CI experiences involve the same commitment to or enactment of the CI approach described by the Ontario Ministry of Education (OLNS, 2007, 2010). Therefore, teachers were asked to rate the frequency with which they engaged in 19 CI-related activities using a four-point scale $(0=$ never; 
4=always). Table 1 presents the descriptive statistics and factor loadings for these items.

The most commonly experienced activities included: "Gather evidence of student learning through observations" $(M=3.51 ; S D=.81)$; "Gather evidence of student learning through artifacts (e.g., student work)" ( $M=3.33 ; S D=.96)$; and "Apply learning from the inquiry to your instructional practice" $(M=3.33 ; S D=.82)$. While co-planning with other teachers was a relatively common activity, co-teaching was not. CI activities that teachers engaged in least included: "Gather evidence of student learning through surveys" $(M=1.59 ; S D=1.35)$; "Co-teach lessons" $(M=2.14 ; S D=1.46)$; and "Gather evidence of student learning through written teacher reflection (e.g., journals)" $(M=2.25 ; S D=1.37)$. In our findings, it is worth noting that a number of SDs have quite high values compared to the mean. Teachers generally reported engaging in a number of CI-related activities. While some activities were consistently reported as being a part of the CI cycle, the reporting of engagement in other activities was much more varied. The varied engagement with certain activities may reflect the CI foci, practices and approaches to CI within a school or across districts, and the employment of CI activities by teachers of different grades (e.g., elementary, junior). The variability in responses likely mirrors the variability in the way teachers experienced $\mathrm{CI}$ in their particular contexts.

EFA provided a means to examine the dimensionality of teachers' CI activities. Parallel analysis and Velicer's MAP tests both identified one dimension. Subsequent analyses include restricting the factor structure to a one-factor solution, and our model supported unidimensionality among the items to explain $40.85 \%$ of the variance. Sampling adequacy was reached with the KMO test at 0.90 for all items and a significant value for Bartlett's Test of Sphericity $\left(\chi^{2}(171, N=232)=2589.8, p<0.001\right)$. Table 1 presents the descriptive statistics and factor loadings for these items. 
Teacher engagement in CI included a variety of experiences from the preparation or setting up for CI, to gathering evidence, and working collaboratively to participate in co-analysis and to identify next steps. Overall, teacher engagement in CI activities focused on determining the target of the inquiry within particular educational contexts. These initial efforts shaping specific questions of inquiry are discernable from teachers' actions to mobilize plans involving gathering data for analysis, and separate from collaboration to inform next steps. Evidently, question items focused on teachers' participation as collaborators in data analyses and collaboration to complete the CI cycle had the strongest factor loadings in this subscale.

\section{INSERT TABLES 1}

The focus group data provided diverse illustrative and contextualized examples of teachers engaging in the CI activities addressed in the survey; however, these examples all used elements of the factor constructs described above. In the following paragraph we present one example of teachers describing their CI process as a means of highlighting the enactment of the factor constructs listed in Table 2.

The team of elementary teachers set up the inquiry by deciding first to "look at where there were gaps in math teaching and learning." Having collectively selected this broad inquiry focus, the teachers "went in and did a lesson with the kids, recorded what they were saying and doing during math class, and then came back and looked at it as a group." In carrying out these early activities_-gathering evidence of student learning through observations then discussing and co-analyzing it - the teachers realized:

We could see where students were capable but weren't sharing, in some way, the information that they had and, and that's where it breaks down, right? Because you don't 
know why the child got 56-whether they just copied it or whether they actually did the operation.

Accordingly, the teachers refined their inquiry focus, identifying the following specific inquiry goal: "To close in that achievement gap through making the kids' thinking visible." In pursuit of this goal, the teachers co-planned pedagogical actions. "We created a checklist and kind of taught to that." Next, the teachers "all went into the classrooms together and co-taught and documented," then continued to repeat the collaborative inquiry cycle: "We just kept refining it." Eventually, reflecting on student learning, the teachers were able to identify a positive outcome of their CI work:

By the end of it, even the little wee ones were able to share more of what their thinking was. So even if their answer was wrong, you could see they were on the right track, in terms of the math, because they had shown us what they could do.

This descriptive example coupled with survey data on teachers' CI activities provides a baseline conception for this study of CI as experienced by Ontario teachers. In the following section we further draw from the data to illuminate teachers' perspectives on factors that enhanced their CI experiences, factors that inhibited their experiences, and perceived significant outcomes of their CI experiences. Survey data (descriptive statistics and EFA) followed by focus group data (i.e., thematic analyses) related to each of these aspects are described below.

\subsection{Factors that Enhanced CI}

In the survey, teachers were asked to identify the helpfulness of 15 different resources and structures commonly associated with CI using a four-point scale $(0=$ not helpful; 4=extremely helpful). Teachers reported the following as most helpful to their CI learning: "Evidence collected from observations of students during lessons" ( $M=3.68 ; S D=.66)$; "Student 
work samples" $(M=3.62 ; S D=.72)$, and "Release time to collaborate with peers (within your school)" $(M=3.40 ; S D=.98)$. The least helpful factors included: "Research partners" $(M=2.20$; $S D=1.46)$; Data from common assessments" $(M=2.32 ; S D=1.34)$; and "The School Effectiveness Framework" $(M=2.47 ; S D=1.26)$. While teachers were generally consistent in their strong valuing of release time to work with peers and of collecting student-level data, the variability concerning the other factors suggests that teachers had differing experiences, perhaps due to the dissimilar supports made available to teachers in diverse contexts. Table 2 presents the descriptive statistics and factor loadings for factors that enhanced teachers' CI experiences.

We used the same procedure of evaluating the number of factors to retain and both PA and MAP test both revealed one dimension for the group of items. Sampling adequacy was reached for KMO measure of sampling adequacy was 0.87 for all items and Bartlett's Test of Sphericity was significant $\left(\chi^{2}(105, N=84)=809.1, p<0.001\right)$. The EFA was restricted to a onefactor solution supporting a simple structure and unidimensionality for factors that enhanced CI to explain $49.33 \%$ of the variance. The factor highlights a number of CI supports including resources and targeted support from the ministry, embedded school opportunities, partnerships, and external collaboration such as how to collect and analyze student-level data in the classrooms and CI resources that were relevant and targeted specifically to teachers' inquiry foci enable teachers to adapt CI to their contexts.

\section{INSERT TABLE 2}

While the survey questions focused on the helpfulness of particular types of resources, the focus group discussions with teachers revealed relational or experiential factors: (a) teacher choice of inquiry focus, (b) acknowledging CI learning takes time, (c) acknowledging teachers as 
experts, (d) establishing trusting relationships with colleagues, and (e) seeing student success from CI.

6.2.1. Teacher choice of inquiry focus. Teachers valued being able to choose their own topic of focus for CI work, rather than having the focus externally imposed. "What's important is deciding as a group what you want to do it on. Not someone walking in and saying 'Okay, we're all going to do problem-solving.", Teachers identified that having agency in this decision motivated their involvement: "It has to come from the heart of the teachers or they're not going to own it." Teachers also identified that when they directed the inquiry focus the resultant learning was more likely to be useful. "When you get to choose what you want to research, what you want to learn, the insights that you gain are a lot more valuable in the end."

6.2.2. Acknowledging CI learning takes time. Teachers emphasized the importance of acknowledging that for CI to be successful, considerable time must be invested: 'It's not about throwing it all out at you over a couple of days - it might be a year to get it, to get your head wrapped around what it looks like. Then the following year you start actually making it happen." Teachers referred to CI as a process that cannot be reduced or compacted: "It really needs to run its course and evolution." Despite the natural desire for quick results, administrators and participating teachers themselves need to be prepared to invest the time without premature expectations of results. "It's very easy to try to dive in too quickly and get really overwhelmed and frustrated and discouraged, but if you see that it's okay to just move slowly-giving yourself that permission is really, really key."

6.2.3. Acknowledging teachers as experts. Teachers described appreciation for the fundamental premise of CI: that teachers are experts. "I find it so, so useful when we're given the time to learn from each other." Teachers expressed satisfaction that this professional learning 
structure grows naturally from their own and their colleagues' personal and practical experiences: "I've found the most value in CI because it's something that evolves from me being in the classroom." Teachers voiced deep appreciation for the recognition that they and their peers are in a better position than external experts to address, collaboratively, the contextualized professional learning they need:

Here's an opportunity for me to talk to probably the most knowledgeable people, my peers, and be able to come up with a solution. It's not someone telling me from abovewho hasn't been in a classroom potentially for, you know, 6 to 8 years - telling me what to do. It's somebody else who's living what I'm living.

\subsubsection{Establishing trusting relationships with colleagues. Within the collaborative}

relationship, teachers described the need to feel safe. "There needs to be a lot of trust and support before you can even tackle a project together...that partnership needs to be developed first." CI activities put teachers in positions of risk: “as teachers we feel vulnerable...I don't want to be told that I'm not doing a good job.” The collaborative work can highlight a teacher's lack of knowledge or experience. "I had a lot of reservations because of the difference in our opinions and our teaching styles and age-gap too. I was a little nervous working with a senior teacher when I was a first-year teacher." For the work to progress effectively, teachers need to be able to trust their collaborators enough to enter into those spaces of vulnerability: "If everybody's comfortable in their own skin, you can learn...it's important for us to be able to give up that little bit of pride and say 'No, I don't know what I'm doing. Someone has to help me with this.' Sometimes teachers struggle with that." When the trust is in place, the collaborative learning is more powerful: 
The junior-intermediate wing... we tend to meet around the coffee table each morning... having that background and familiarity with one another has helped tremendously...The comfort level allows for us to challenge each other...to be hard on ourselves in front of each other.

Seeing student success result from CI. Finally, teachers explained that their CI experiences were enhanced when they were able to identify a direct benefit to student achievement. "I always come back to the kids because if they weren't getting anything out of it, then I wouldn't find it of any value." To be convinced of CI's effectiveness, teachers needed to see the connection from teacher learning to student learning:

Teaching grade one, there's always in your mind: these kids have to be able to read by the end of the year. And with a different approach, my fear was, will they get to where I need them to be?... Now that I'm seeing the evidence of what's gone on over the year, it makes sense. So... seeing is believing. Seeing that evidence is what, myself as an educator, what I need.

\subsection{Factors that Inhibited CI}

Teachers reported the extent to which factors inhibited their CI learning using a fourpoint scale ( $0=$ significantly inhibited; $4=$ did not inhibit). The three most inhibiting factors were: "Students' lack of willingness to try new things" $(M=3.05 ; S D=1.19)$; "Lack of ability to make sense of the evidence I gather (i.e., analysis of evidence) $(M=2.80 ; S D=1.17)$ "; and "Lack of willingness of those I am working with to listen to my ideas" $(M=2.80 ; S D=1.31)$. Factors identified as less inhibiting to CI learning included: "Amount of time required of me in the CI process and its impact on my teaching time" $(M=2.35 ; S D=1.35)$; "Shifts in school focus, 
direction, or activity that are introduced during our CI" $(M=2.51 ; S D=1.24)$; and "Ability to assess the impact of the inquiry" $(M=2.69 ; S D=1.12)$.

EFA analyses revealed one dimension at initial extraction on both the PA and MAP test. Significant values for sampling adequacy were obtained including KMO values of 0.87 for all items and significant value for Bartlett's Test of Sphericity $\left(\chi^{2}(36, N=225)=1161.3, p<0.001\right)$. The one-factor solution explained $54.38 \%$ of the variance representing different aspects of teacher and student "buy-in" into the processes and enactment of CI practices in the classroom, and the impact or value of focused CI on teaching and learning outcomes (Table 3).

\section{INSERT TABLE 3}

Our analysis of focus group data yielded nine factors that inhibited CI learning, with most relating closely to survey findings. The factors are presented in Table 7 with supporting quotations. In summary, the first four factors represent various aspects of the perception that CI may take up too much of teachers' time. Teachers described resenting CI when it felt like another imposed layer of work, and when they could not see the relevance to their own classrooms. Some teachers felt that CI was inefficient as a PD structure, voicing frustration with the inquiry approach and suggesting preference for a direct "transmission learning model." Teachers also expressed concerns about the time CI took away from their work with students.

Additionally, teachers perceived that CI learning was inhibited by the fear that their professional skills or knowledge would be "judged, and found wanting." Teachers felt this fear in contexts of professional discussions with colleagues and when teaching in front of colleagues. Teachers also identified their lack of confidence in external experts too far removed from classroom teaching. Further, particularly in the early stages of CI, teachers described feeling insufficiently supported by the administrators and external personnel during CI. As a result, 
teachers revealed discomfort due to unfamiliarity and low confidence with the new practices and pedagogical approaches they were designing and exploring. Finally, teachers voiced considerable frustration with their inability to respond to the externally imposed requirement to provide evidence that supports the success and effectiveness of their CI learning.

\section{INSERT TABLE 4}

\subsection{Perceived Significant Outcomes from CI Learning}

Survey and focus group data explored teachers' perspectives on significant outcomes from CI related to both teacher and student learning. In relation to teacher outcomes, the survey presented 14 statements that reflected potential outcomes as suggested by previous literature to which teachers indicated their level of agreement ( $0=$ strongly disagree; $4=$ strongly agree). Table 8 reports the means and factor loading values after rotation. Statements with the strongest agreement fell within one factor and related to interactions with students and tangible benefits in teaching and learning: "CI has influenced me to design instruction to engage students" $(M=3.33$; $S D=.96)$; "CI has influenced me to differentiate instruction for my students" $(M=3.20 ; S D=1.03)$; and "CI has influenced me to incorporate student voice, perspectives, and interests" $(M=3.20$; $S D=1.03$ ). Statements that teachers agreed with the least included: "I was encouraged to spend time on my CI professional learning" $(M=2.18 ; S D=1.29)$; "I have become an instructional leader in my school as a result of my engagement in $\mathrm{CI}$ " $(M=2.20 ; S D=1.44)$; and "CI has influenced me to co-learn with school administrators" $(M=2.73 ; S D=1.21)$. Teacher responses illustrate the impact of CI in changing their practices, exploring methods for differentiated instruction, and to collect student-level data in their classrooms. There is variance in teacher's reports on the impact of $\mathrm{CI}$ on their individual PD, and fewer respondents agreed that CI led to additional leadership opportunities. 
The factor analysis for the 14 statements for perceived outcomes of CI yielded significant values for both the KMO with 0.94 for all items, and Bartlett's Test of Sphericity ( $\chi^{2}$ (91, $N=243)=2968.8, p<0.001)$. EFA analyses during initial extraction revealed one dimension through PA and two factors on the MAP test. We concluded on the one-factor solution, which provided a simple structure to explain $59.20 \%$ of the variance. The questions focused on CI's direct influence on teaching and learning including tangible benefits of engaging in CI, opportunities and leadership, and endorsement and attitudes towards CI as a professional learning model. Moreover, opportunities afforded from participation in CI include cultivating the space for dialogue with local and external partners, and adopting a leadership stance in the process. Teachers' professional growth and changes in stance (own conceptions, attitudes, and beliefs) about CI as an effective professional learning opportunity were strongly noted.

\section{INSERT TABLE 5}

In the analysis of focus group data, CI outcomes that emerged as significant for teachers included: (a) more teachers talking, (b) informal CI, (c) increased teacher confidence to take risks/shift practices, and (d) increased attention to teacher reflection and ongoing teacher learning.

6.4.1. More teachers talking. As a result of their experiences with CI, teachers described a workplace shift. "More teachers are talking. You see it." Teachers identified that they were now more inclined to work together instead of alone. "I've noticed teachers have come out of their classroom and it's not that isolated 'I'm an entity all to myself.' We've started to talk with one another a lot more, on a professional level." Teachers described a new culture of collaboration, where they were more likely to talk about their practice, and to seek and offer 
professional advice in an environment where "You're not alone. We can network. We can do this."

6.4.2. Informal CI. In addition, experiences with CI have encouraged teachers to work collaboratively and learn from each other beyond formal CI structures: "When there's a little problem you just chat about it instead. You're not always waiting for a CI." Some teachers observed that CI had become a regular, integrated aspect of their professional practice: "If you're truly in it, the inquiry, it doesn't really end, because as you go on with it, you're going to figure out something else...go sideways or deeper...it's just something you do. It's a habit."

6.4.3. Increased teacher confidence to take risks/shift practices. Teachers identified that as a result of CI structures, notably support from colleagues, they gained the confidence to take risks and shift practices. "You become, I guess, more of a risk-taker in the classroom. You get that confidence in your classroom that you might not have tried something on your own, whereas if you do this as a group, you know, there's strength in numbers, right?”

\subsubsection{Increased attention to teacher reflection and ongoing teacher learning. Teachers} also recognized that engagement with CI has caused them to examine their own practices more reflectively and critically. "We can't just teach anymore and hope that's going to make a difference. This is actually getting us to look and measure what we're doing." As a result of their involvement in CI, teachers described a shifting perspective that acknowledged the importance of teacher learning as well as student learning:

You start noticing it's the changes $I$ need to make and my needs right now that have the biggest impact on student learning... when we first started it was: what's wrong with the students? Now it's: what teacher learning do we need to dictate changes in student learning? Now we're looking at $u s$. 
In addition to expressed outcomes for teachers, we asked survey respondents to indicate how their CI involvement had impacted their students' learning across nine indicators. Table 6 presents teachers reports on the extent to which they observed changes in student engagement as a result of $\mathrm{CI}(0=$ no extent; $4=$ very large extent $)$. The greatest impact they reported was that students were "Working collaboratively on shared tasks" $(M=2.96 ; S D=1.01)$; "Displaying increased confidence in their learning" $(M=2.83 ; S D=1.05)$; and "Demonstrating increased engagement in classroom activities" $(M=2.78 ; S D=1.11)$. In contrast, the smallest impact was reported for those activities related to "Fewer absences" $(M=1.37, S D=1.43)$; "Displaying increased ability to work independently" $(M=2.40, S D=1.07)$; and "Increased skill at selfassessment" $(M=2.43, S D=1.06)$. The majority of teachers reported that the impact of CI on student learning outcomes was demonstrated through noticeable changes in students' approaches and confidence in their own learning. The number of factors to be retained was one for both PA and Velicer's MAP tests with significant values for KMO with a value of 0.93 and significant Bartlett's Test of Sphericity $\left(\chi^{2}(36, N=248)=1632.4, p<0.001\right)$. The final solution was maintained and explained $65.13 \%$ of the variance.

\section{INSERT TABLE 6}

During focus groups, teachers described a variety of positive outcomes on students, including (a) students adopting a CI mindset, (b) student empowerment through CI involvement, and (c) students' academic growth.

6.4.5. Students adopting a CI mindset. Teachers identified that, as a result of the CI they were carrying out, their students also adopted some of the habits of mind that the teachers were displaying: "I think too when, as teachers, you become risk-takers with each other, which we have, then they absolutely are risk-takers in the classroom." Teachers also noticed students 
showing increased confidence to initiate self-directed learning: "I will go find that out!" and to share learning with others: "Oh, I know how to do that. I'll show you." A teacher explained: "They're helping each other along the way, just like we are." Another observed that the CI mindset is "translated to the students. They get it from each other and they get it from me. So, we're evolving, but they're also evolving at the same time as well."

6.4.6. Student empowerment through CI involvement. Teachers described their perception of CI as a student-driven process: "You're the little engine that's the wheel, but it's their responses, their thinking and their needs that are driving it...Their needs are driving our professional practice." As a result of the recognition of their centrality in the CI process, students feel empowered. A teacher explained, "I've seen all sorts of kids in our school embrace sharing their thinking with the adults and that's the big thing. They feel empowered.” Student empowerment occurs when teachers attend to students' experiences of learning. As a result, the roles shift, and teachers become co-learners: "Kids are actually teaching you too...it's great to say: 'I'm learning with you.",

\subsubsection{Students' academic growth. Teachers also offered examples of their CI} involvement directly impacting student academic growth. As a result of CI experiences, one teacher explained that her students were more inclined to refine their work:

If I look at all my years of teaching, my students now for sure are much more reflective, and much more willing to go back and say: 'You know what? I can make this better and I'm going to' as opposed to: 'Oh good, I'm done.'

Another teacher identified that her CI experiences had enabled her to support a number of students advance in math: 
Writing my kids' final report cards and having a good handful of children who went from Level 1 and 2 in math... at the beginning of the year I felt rather hopeless-like I don't know how I'm ever going to move them...they are [now] doing exactly what I was hoping they would be doing.

Overall, it is evident that teachers perceive benefits to CI as a professional learning model. Data from across survey and focus groups suggest that outcomes directly related to teacher practice and student learning hold the most impact for teachers. Secondly, there is evidence that teachers' conceptions and practices of professional learning are changing to value collaborative modes of inquiry and the establishment of dialogic learning groups.

\section{Discussion}

Our primary purpose in this research was to collect data from teachers across a system of education on the impact and functionality of CI as a professional learning model. The province of Ontario has systematically supported CI over the past five years across its school districts as a dominant model for elementary teacher professional learning. Like many other systems of education, Ontario has elected to endorse CI because it is a job-embedded, collaborative model that focuses teacher learning on a shared problem of practice through data-based inquiry (Butler \& Schnellert, 2012; Opfer \& Pedder, 2011; Webster-Wright, 2009). We recognize that the approach endorsed in Ontario represents one approach to CI, and are cognizant that this systemic effort toward networked professional learning operates within an emerging global neoliberal framework (Ball, 2012) beginning to influence Canadian education (Davidson-Harden, Kuehn, Schugurensky, \& Smaller, 2009). However, we also recognize that the CI framework presented in this research can lead to diverse teacher inquiries and thus has latitude for teacher-based interests related to specific teacher needs. While several case studies have provided initial 
empirical evidence that $\mathrm{CI}$ has merit for individual teacher learning few studies have provided data from a large-scale sample of teachers on their responses to systematic and prolonged efforts to use $\mathrm{CI}$ as a professional learning model for educator development.

Drawing data from nearly 300 elementary teachers, this study emphasizes factors teacher perceive enhance CI, including: (a) autonomy to choose their inquiry focus, (b) interacting with peer teachers and external experts as sources of knowledge, (c) improved student outcomes as a result of CI actions, and (d) access resources that describe CI processes. The focus group findings highlighted the value teachers place on establishing trusting relationships within CI contexts and their satisfaction in regarding teacher colleagues as knowledgeable experts.

Dominant factors inhibiting teachers' CI experiences included (a) students' unwillingness to try new things, (b) teachers' own lack of confidence to try new things, (c) unwillingness of colleagues to listen to teachers' ideas, and (d) the perception that $\mathrm{CI}$ infringed too much on instructional time. Focus group findings additionally highlighted inhibiting factors such as fear of exposing personal teaching weaknesses in front of colleagues, lack of confidence in out-oftouch 'experts,' and difficulty and frustration meeting the accountability requirements of external stakeholders seeking demonstration of CI success.

Regarding significant outcomes of CI, survey data indicated that teachers identify tangible benefits in teaching and learning and have come to value CI as a vehicle for professional learning. Focus group data highlighted that more teachers are talking about their practice and engaging in informal CI, are more consciously reflective and attuned to ongoing teacher learning, and are more confident to take risks and shift practices.

In relation to our theoretical framework, findings from this study suggest that teachers' CI work is variable in the extent to which it embodies the OLNS's (2010) seven characteristics 
of teacher inquiry (i.e., relevant, collaborative, reflective, reasoned, adaptive, reciprocal, and iterative). These data suggest that while teachers value the 'relevant,' 'reflective,' and 'collaborative' aspects of CI they are still working to develop skills and processes to meaningfully engage in the 'iterative,' 'reasoned,' 'adaptive,' and 'reciprocal' aspects.

That teachers' CI work is 'relevant' was strongly supported by responses specifically indicating that teachers needed their learning to "be connected to the student's desk." The 'reflective' and 'collaborative' nature of teachers' CI work was also strongly supported by the data. Teachers repeatedly reported that selecting their own problem of practice in collaboration with peer teachers was an important impetus for their learning, and that they valued the opportunity to engage in inquiry through collaboration with their teacher colleagues.

Cyclical learning, where one inquiry leads logically into the next, is integral to CI. However, our data indicate that teachers are not fully engaging in this 'iterative' aspect. The survey data point to neutral or low levels of collaboratively refining and identifying new inquiry questions and repeating the CI cycle. While qualitative data were more promising, there were still significant concerns about time, space, and administrative influence to continue CI learning. Instead, what appears more common is the selection of a new inquiry focus each academic year. While this approach still adheres to an iterative practice of monitoring and reflecting upon the impact of pedagogy on student achievement, it may not promote sustained and deep learning related to a core problem of practice.

At present, it appears that teachers primarily engage in activities related to 'setting-up' their CI projects (i.e., co-selecting focus of inquiry, co-learning about focus of inquiry, and coplanning steps for instruction). Given that $\mathrm{CI}$ is a relatively new professional learning structure, it is probable that teachers lack understanding and/or experience of the complete CI cycle. Data 
from our survey suggest that teachers appreciate and use resources that help them understand CI; for example, one teacher noted that she values texts that "walk through the steps of CI." However, focus group data indicated teachers often do not feel sufficiently supported in structuring CI projects and activities. As one teacher put it, "We're thrown into these things, but we're not really guided as to the way we should really go."

With regard to the 'reasoned' or analytical aspect of CI, although teachers highly valued seeing evidence of increased student outcomes as a result of CI learning, survey data indicated that they did not frequently engage in evidence-based CI activities (i.e., gathering evidence of student learning) or in co-analyzing evidence. While focus group data indicated teachers were engaging in evidence-based activities, there were limited explicit examples of this practice. Given that the 'reasoned' aspect of the CI model is enacted to a lesser extent, teachers may need additional support in understanding how to collect, co-analyze, and interpret data to stimulate adaptive CI learning. This need to support teachers in increasing their data literacy has been preliminarily identified in previous research (DeLuca et al., 2015; Nelson et al., 2008), and appears to be a critical issue in order to fulfill the intentions of CI as a data-based form of professional learning (Kennedy et al., 2011, Robinson et al., 2010; Vineyard, 2010).

Connected to the need for data literacy, we add the need for teachers to become 'theoretically literate.' The 'reciprocal' aspect of CI refers to the connecting of theory and practice, and there was little evidence of teachers making use of theory, research, and board level data, aside from some interactions with 'experts.' Few teachers in our focus groups discussed using research articles or theoretical frameworks to guide their inquiry and data analysis. It appears that teachers are relying on other teachers to support their solutions to problems of practice. This 'sharing to solve problems' is an initial step to addressing pedagogical challenges, 
but does not represent a research-perspective towards professional inquiry (Groundwater-Smith \& Mockler, 2007). In select cases, teachers reach out to 'experts' to supply them with the research knowledge to guide their inquiries. While this is a potentially useful strategy, a more far-reaching strategy would be to support teachers in their understandings about educational research, theoretical frameworks, and systemic data, thereby enabling them to enhance the 'reasoned' and 'reciprocal' aspects of their CI activities. In this way, CI research and practice needs to more fully explore the ethical (Campbell, 2003), evidentiary, and theoretical dimensions of this form of practitioner research (Groundwater-Smith \& Mockler, 2007).

In examining the factors that inhibit $\mathrm{CI}$ across a system, our data suggest that personal and social factors may be more important than previously recognized. While previous studies have identified the need for teacher 'buy-in' (DeLuca et al., 2015; Ermeling, 2010; Nelson \& Slavit, 2008), data from this study identify the following personal and social factors as strong potential inhibitors to CI: (a) a lack of student willingness to try new things, (b) teachers' lack of confidence to try new things, (c) a lack of willingness by teachers to listen to others' ideas, and (d) a fear of exposing personal teaching weaknesses. Given the collaborative, public, and experimental nature of CI, these factors are not surprising. However, there is a need to build trust and confidence throughout CI processes, which must extend from classroom teaching to teacher learning groups. As the qualitative data suggest, when these factors are elevated, CI can powerfully cultivate professional learning communities, strengthening teacher relationships and promoting pedagogical development.

Based on our analysis of teachers' responses, it is evident that there is value in continuing to pursue CI as a professional learning model. However, it is also evident that teachers need additional support to engage CI effectively, particularly in the collection and use of data and the 
integration of educational research. Future research should target these areas and provide empirical examples of how to increase the data and research literacy of teachers both in-service and pre-service whilst engaging in CI. Secondarily, teachers need tools to monitor their own learning alongside changes in student level data as they engage in CI activities. At present, it appears that teachers engage high levels of collaboration and dialogue on their problems of practice but are not fully tracking their learning to justify the outcomes of CI and to identify logical new inquiries for iterative and adaptive learning. Finally, there is a need to attend to the social and personal factors that limit individual teachers' participation in CI.

\subsection{Limitations and Future Directions}

While this research presents important findings related to $\mathrm{CI}$ as a systemic professional learning approach, there are three limitations worth considering. First is the lack of direct observation of CI practices. Observational data would contribute to a more thorough and comprehensive examination of CI within this system; other researchers have begun this work (e.g., Ermeling, 2010; Nelson, 2009; Nelson et al., 2012; Windschitl et al., 2011), however, additional observational evidence is warranted. Second, data directly addressing students' experiences would enhance the examination of the CI phenomenon. Two types of data would be of value: student achievement data as linked to teacher CI learning and students' perspectives on their changing learning experience as a result of teacher CI learning. To date, very few studies provide conclusive evidence on the effects of $\mathrm{CI}$ to increase student achievement. However, our research indicates that teachers perceive that the most significant outcomes of CI relate to interactions with students and tangible benefits in teaching and learning. Hence, a next step for future research is to examine evidence of these perceptions and to explore how CI influences student achievement and learning. Finally, data from additional stakeholders would further 
benefit this examination of CI: to hear not only from teachers and students, but also from parents, administrators (e.g., principals), and school district personnel within and beyond the Ontario context. Tied to this is the need to recognize that there is no single 'best practice' for doing CI. Despite an emerging global neoliberal agenda that promotes, and in some instances mandates, singular models for teaching and professional learning (Ball, 2012), we assert that there is an increased need to further diversify models of professional learning by exploring differences in the enactment of CI alongside other practitioner-research PD models.

\subsection{Conclusions}

Despite limitations, this study provides novel insights into CI as a model for systemic inservice learning. There are clear positive outcomes of CI when teachers are supported across various inquiry stages. Moreover, there is initial evidence that teachers' relationships and inschool culture is changing as a result of CI to include more teacher talk and informal learning, increased teacher confidence to take pedagogical risks, and greater attention to teacher reflection and systematic teacher learning. As CI is still relatively new within the professional learning landscape, this early evidence is promising as an indicator that CI has the potential to not only enable teacher learning about a shared problem of practice but, perhaps more importantly, shift teachers' approaches to professional learning toward more collaborative, reasoned, reciprocal, and iterative ends. 


\section{References}

Ball, S. (2012). Global education inc.: New policy networks and the neo-liberal imaginary. New York, NY: Routledge.

Baglin, J. (2014). Improving your exploratory factor analysis for ordinal data: A demonstration using FACTOR. Practical Assessment, Research \& Evaluation, 19(5), 1-5.

Blunch, N. (2013). Introduction to structural equation modeling using IBM SPSS Statistics and Amos (2nd ed.). Thousand Oaks, CA: Sage.

Borko, H. (2004). Professional development and teacher learning: Mapping the terrain. Educational Researcher, 33(8), 3-15.

Butler, D. L., \& Schnellert, L. (2012). Collaborative inquiry in teacher professional development. Teaching and Teacher Education, 28(8), 1206-1220.

Butler, D. L., \& Winne, P. H. (1995). Feedback and self-regulated learning: A theoretical synthesis. Review of Educational Research, 65(3), 245-281.

Byrne-Jimenez, M., \& Orr, M. T. (2007). Developing effective principals through collaborative inquiry. New York, NY: Teachers College Press.

Campbell, E. (2003). The ethical teacher. Berkshire, UK: Open University Press.

Clausen, K. W., Aquino, A. M., \& Wideman, R. (2009). Bridging the real and ideal: A comparison between learning community characteristics and a school-based case study. Teaching and Teacher Education, 25, 444-452.

Clauset, K. H., \& Murphy, C. U. (2012). Creating synergy: Cycle of inquiry shifts learning teams into high gear. Journal of Staff Development, 33, 30-33.

Comber, B. (2013). Teachers as researchers: A ‘fair dinkum’ learning legacy. English in Australia, 48(3), 54-61. 
Comrey, A. L., \& Lee, H. B. (1992). A first course in factor analysis (2nd ed.). Hillsdale, NJ: Erlbaum.

Cordingley, P., Bell, M., Evans, D., \& Firth, A. (2005). The impact of collaborative continuing professional development (CPD) on classroom teaching and learning. Review: How do collaborative and sustained CPD and sustained but not collaborative CPD affect teaching and learning? London, UK: EPPI-Centre, Social Science Research Unit, Institute of Education, University of London.

Costello, A. B., \& Osborne, J. W. (2005). Best practices in exploratory factor analysis: Four recommendations for getting the most from your analysis. Practical Assessment, Research \& Evaluation, 10, 1-9.

Cunningham, D. (2011). Improving teaching with collaborative action research. Alexandria, VA: ASCD.

David, J. L. (2009). Collaborative inquiry. Educational Leadership, 66(4), 87-88.

Davidson-Harden, A., Kuehn, L., Schugurensky, D., \& Smaller, H. (2009). Neoliberalism and education in Canada. In D. Hill (Ed.), The rich world and the impoverishment of education: Diminishing democracy, equity and workers' rights. New York, NY: Routledge.

Davies, B., \& Bansel, P. (2007). Neoliberalism and education. International Journal of Qualitative Studies in Education, 20(3), 247-259.

DeLuca, C., Shulha, J., Luhanga, U., Shulha, L. M., Klinger, D. A., \& Christou, T. (2015) Collaborative inquiry as a professional learning structure for educators: A scoping review. Professional Development in Education, 41(1), 640-670.

Donohoo, J. (2013). Collaborative inquiry for educators: A facilitator's guide to school 
improvement. Thousand Oaks, CA: Corwin.

Elmore, R. F. (2000). Building a new structure for school leadership. Washington, DC: The Albert Shanker Institute.

Emihovich, C., \& Battaglia, C. (2000). Creating cultures for collaborative inquiry: New challenges for school leaders. International Journal of Leadership in Education, 3(3), $225-238$.

Ermeling, B. A. (2010). Tracing the effects of teacher inquiry on classroom practice. Teaching and Teacher Education, 26(3), 377-388.

Fabrigar, L. R., \& Wegener, D. T. (2012). Exploratory factor analysis. New York, NY: Oxford University Press.

Fabrigar, L. R., Wegener, D. T., MacCallum, R. C., \& Strahan, E. J. (1999). Evaluating the use of exploratory factor analysis in psychological research. Psychological Methods, 4, 272299.

Field, A. P. (2009). Discovering statistics using SPSS: And sex and drugs and rock ' $n$ ' roll (3rd ed.). London: Sage publications.

Forey, G., Firkins, A. S., \& Sengupta, S. (2012). Full circle: Stakeholders' evaluation of a collaborative enquiry action research literacy project. English Teaching: Practice and Critique, 11(4), 70-87.

Galligan, G. (2011). Collaborative inquiry, teacher efficacy, and writing achievement at Lake Shore elementary school. (Doctoral dissertation). Retrieved from ProQuest Dissertations \& Theses database. (UMI No. 3449832)

Garrido, L. E., Abad, F. J., \& Ponsoda, V. (2013). A new look at Horn's parallel analysis with ordinal variables. Psychological Methods, 18(4), 454-474. 
Given, H., Kuh, L., LeeKeenan, D., Mardell, B., Redditt, S., Twombly, S., (2010). Changing school culture: Using documentation to support collaborative inquiry, observation, documentation, and reflection to create a culture of inquiry. Theory Into Practice, 49, 3646.

Groundwater-Smith, S., \& Mockler, N. (2007). Ethics in practitioner research: An issue of quality. Research Papers in Education, 22(2), 199-211.

Hannay, L., Wideman, R., \& Seller, W. (2010). Professional learning to reshape teaching. Toronto, ON: Elementary Teachers' Federation of Ontario.

Holgado-Tello, F. P., Chaćon-Moscoso, S., Barbero-Garcia, I., \& Vila-Abad, E. (2008). Polychoric versus pearson correlations in exploratory and confirmatory factor analysis of ordinal variables. Quality \& Quantity, 44(1), 153-166.

Hord, S. M., Roussin, J. L., \& Sommers, W. A. (2010). Guiding professional learning Communities: Inspiration, challenge, surprise, and meaning. Thousand Oaks, CA: Corwin Press.

Horn, J. L. (1965). A rationale and test for the number of factors in factor analysis. Psychometrika, 30(2), 179-185.

Horn, I. S., \& Little, J. W. (2009). Attending to problems of practice: Routines and resources for professional learning in teachers' workplace interactions. American Educational Research Journal, 47(1), 181-217.

Huffman, D., \& Kalnin, J. (2003). Collaborative inquiry to make data-based decisions in schools. Teaching and Teacher Education, 19(6), 569-580.

Hutcheson, G., \& Sofroniou, N. (1999). The multivariate social scientist: Introductory statistics using generalized linear models. Thousand Oaks, CA: Sage Publication. 
Kaiser, H. F. (1960). The application of electronic computers to factor analysis. Educational and Psychological Measurement, 20, 141-151.

Kaiser, H. F. (1974). An index of factorial simplicity. Psychometrika, 39(1), 31-36.

Kennedy, A., Deuel, A., Nelson, T., \& Slavit, D. (2011). Requiring collaboration or distributing leadership? Phi Delta Kappan, 92(8), 20-24.

Kline, P. (1999). The handbook of psychological testing (2nd ed.). London: Routledge.

Lakes, R. D., \& Carter, P. A. (2011). Neoliberalism and education: An introduction. Educational Studies, 47(2), 107-110.

Little, J. W. (2002). Locating learning in teachers' communities of practice: Opening up problems of analysis in records of everyday work. Teaching and Teacher Education, $18(8), 917-946$.

Lee, T. (2009). Educational leadership for the 21st century: Leading school improvement through collaborative enquiry. Paper presented at the Canadian Association for Studies in Educational Administration conference, Ottawa, ON, May.

Lorenzo-Seva, U., \& Ferrando, P. J. (2006). FACTOR: A computer program to fit the exploratory factor analysis model. Behavior Research Methods, 38(1), 88-91.

Mardia, K.V. (1970). Measures of multivariate skewness and kurtosis with applications. Biometrika, 57, 519-530.

McTighe, J., \& Thomas, R. S. (2003). Backward design for forward action. Using Data to Improve Student Achievement, 60(5), 52-55.

Nelson, T. H. (2009). Teachers' collaborative inquiry and professional growth: Should we be optimistic? Science Education, 93(3), 548-580.

Nelson, T. H., \& Slavit, D. (2008). Supported teacher collaborative inquiry. Teacher Education 
Quarterly, 35(1), 99-116.

Nelson, T. H., Slavit, D., \& Deuel, A. (2012). Two dimensions of an inquiry stance toward student-learning data. Teachers College Record, 114(8), 1-42.

Nelson, T. H., Slavit, D., Perkins, M., \& Hathorn, T. (2008). A culture of collaborative inquiry: Learning to develop and support professional learning communities. Teachers College Record, 110, 1269-1303.

Ontario Literacy and Numeracy Secretariat. (2007). Capacity building series - Professional learning communities: A model for Ontario schools. Toronto: Author.

Ontario Literacy and Numeracy Secretariat. (2010). Capacity building series - Collaborative teacher inquiry. Toronto: Author.

Opfer, V. D., \& Pedder, D. (2011). Conceptualizing teacher professional learning. Review of Educational Research, 81(3), 376-407.

Patton, M. Q. (2015). Qualitative research \& evaluation methods: Integrating theory and practice (4th ed.). Saint Paul, MN: Utilization-Focused Evaluation.

Preacher, K. J., \& MacCallum, R. C. (2003). Repairing Tom Swift's electric factor analysis machine. Understanding Statistics, 2(1), 13-43.

Robinson, M. A. (2010). School perspectives on collaborative inquiry: Lessons learned from New York City, 2009-2010. Philadelphia, PA: Consortium for Policy Research in Education.

Ross, W. E., \& Gibson, R. (Eds.) (2007). Neoliberalism and education reform. New York, NY: Hampton Press.

Schnellert, L., Butler, D., \& Higginson, S. (2008). Co-constructors of data, co-constructors of meaning: Teacher professional development in an age of accountability. Teaching and 
Teacher Education, 24(3), 725-750.

Slavit, D., Nelson, T. H., \& Deuel, A. (2013). Teacher groups' conceptions and uses of studentlearning data. Journal of Teacher Education, 64(1), 8-21.

Snow-Gerono, J. L. (2005). Professional development in a culture of inquiry: PDS teachers identify the benefits of professional learning communities. Teaching and Teacher Education, 21(3), 241-256.

Tabachnick, B. G., \& Fidell, L. S. (2001). Using multivariate statistics (4th ed.). Boston, MA: Allyn and Bacon.

Thompson, B. (2003). Exploratory and confirmatory factor analysis: Understanding concepts and applications. Washington, DC: American Psychological Association.

Tichenor, M., \& Heins, E. (2000). Study groups: An inquiry-based approach to improving schools. Clearing House, 6, 316-319.

Timperley, H., \& Lee, A. (2008). Reframing teacher professional learning: An alternative policy approach to strengthening valued outcomes for diverse learners. Review of Research in Education, 32(1), 328-369.

Velicer, W. F. (1976). Determining the number of components from the matrix of partial correlations. Psychometrika, 41, 321-327.

Vescio, V., Ross, D., \& Adams, A. (2008). A review of research on the impact of professional learning communities on teaching practice and student learning. Teaching and Teacher Education, 24(1), 80-91.

Vineyard, L. (2010). Collaborative inquiry: A strategy for assessing Response to Instruction and Intervention (RtI2) for English learner students. (Doctoral dissertation). Retrieved from ProQuest Dissertations \& Theses database. (UMI No. 3446801) 
Webster-Wright, A. (2009). Reframing professional development through understanding authentic professional learning. Review of Educational Research, 79(2), 702-739.

West, S. G., Finch, J. F., \& Curran, P. J. (1995). Structural equation models with non-normal variables: Problems and remedies. In R. Hoyle (Ed.), Structural equation modeling: Concepts, issues and applications (pp. 56-75). Newbury Park, CA: Sage.

Windschitl, M., Thompson, J., \& Braaten, M. (2011). Ambitious pedagogy by novice teachers: Who benefits from tool-supported collaborative inquiry into practice and why? Teachers College Record, 113(7), 1311-1360.

Winne, P. H., \& Hadwin, A. F. (1998). Studying as self-regulated engagement in learning. In D. Hacker, J. Dunlosky, \& A. Graesser (Eds.), Metacognition in Educational Theory and Practice (pp. 277-304). Hillsdale, NJ: Lawrence Erlbaum.

Zimmerman, B. J., \& Schunk, D. H. (Eds.). (2001). Self-regulated learning and academic achievement: Theoretical perspectives (2nd ed.). Mahwah, NJ: Lawrence Erlbaum Associates, Inc. 


\section{Tables}

Table 1

Means and factor loadings for Teacher Engagement in CI activities

\begin{tabular}{|c|c|c|c|c|}
\hline Item & $n$ & $M(S D)$ & $\begin{array}{l}\text { Unrotated } \\
\text { Factor } \\
\text { Loadings }\end{array}$ & $h^{2}$ \\
\hline \multicolumn{5}{|c|}{$\begin{array}{l}\text { Factor: CI Activities (19 items) } \\
\end{array}$} \\
\hline $\begin{array}{l}\text { Gather evidence of student learning through } \\
\text { observations. }\end{array}$ & 252 & $3.51(.81)$ & .65 & .50 \\
\hline $\begin{array}{l}\text { Gather evidence of student learning through } \\
\text { artifacts (e.g., student work). }\end{array}$ & 256 & $3.33(.96)$ & .51 & .29 \\
\hline $\begin{array}{l}\text { Apply learning from the inquiry to your } \\
\text { instructional practice. }\end{array}$ & 258 & $3.33(.82)$ & .63 & .53 \\
\hline Co-plan next steps for instruction. & 258 & $3.28(.96)$ & .76 & .59 \\
\hline Co-learn about the focus of the inquiry. & 257 & $3.26(.90)$ & .78 & .61 \\
\hline $\begin{array}{l}\text { Collectively select your focus of inquiry and } \\
\text { identify inquiry questions. }\end{array}$ & 256 & $3.22(.92)$ & .46 & .21 \\
\hline $\begin{array}{l}\text { Discuss evidence gathered with your inquiry } \\
\text { team. }\end{array}$ & 257 & $3.21(.98)$ & .68 & .56 \\
\hline $\begin{array}{l}\text { Take specific actions related to your } \\
\text { collaborative inquiry focus when planning } \\
\text { alone. }\end{array}$ & 252 & $3.19(.94)$ & .61 & .64 \\
\hline Use student data to define the inquiry. & 256 & $3.18(.92)$ & .63 & .40 \\
\hline $\begin{array}{l}\text { Co-analyze evidence gathered to improve } \\
\text { practice. }\end{array}$ & 258 & $3.02(1.07)$ & .76 & .70 \\
\hline $\begin{array}{l}\text { Take specific actions related to your } \\
\text { collaborative inquiry focus during your } \\
\text { regular teaching schedule. }\end{array}$ & 253 & $3.08(1.01)$ & .54 & .68 \\
\hline $\begin{array}{l}\text { Collaboratively refine inquiry questions } \\
\text { based on evidence. }\end{array}$ & 255 & $2.96(1.03)$ & .74 & .58 \\
\hline $\begin{array}{l}\text { Co-analyze evidence gathered to make } \\
\text { instructional decisions. }\end{array}$ & 257 & $2.95(1.14)$ & .75 & .63 \\
\hline $\begin{array}{l}\text { Collaboratively identify new inquiry } \\
\text { questions. }\end{array}$ & 255 & $2.84(1.12)$ & .66 & .44 \\
\hline Repeat the collaborative inquiry cycle. & 256 & $2.56(1.38)$ & .54 & .29 \\
\hline $\begin{array}{l}\text { Gather evidence of student learning through } \\
\text { videos/photos. }\end{array}$ & 257 & $2.30(1.45)$ & .43 & .19 \\
\hline $\begin{array}{l}\text { Gather evidence of student learning through } \\
\text { written teacher reflection (e.g., journals). }\end{array}$ & 256 & $2.25(1.37)$ & .47 & .22 \\
\hline Co-teach lessons. & 257 & $2.14(1.46)$ & .50 & .27 \\
\hline $\begin{array}{l}\text { Gather evidence of student learning through } \\
\text { surveys. }\end{array}$ & 257 & $1.59(1.35)$ & .34 & .14 \\
\hline
\end{tabular}

Note. All values $>.30 . h^{2}=$ Communality. Cronbach's alpha $=.91$ 
Table 2

Means and factor loadings for resources that help support CI activities

\begin{tabular}{|c|c|c|c|c|}
\hline Item & $n$ & $M(S D)$ & $\begin{array}{l}\text { Unrotated } \\
\text { Factor } \\
\text { Loading } \\
\end{array}$ & $h^{2}$ \\
\hline \multicolumn{5}{|c|}{ Factor: Supports in CI learning (15 items) } \\
\hline $\begin{array}{l}\text { Evidence collected from observations of } \\
\text { students during lessons }\end{array}$ & 245 & $3.68(.66)$ & .53 & .28 \\
\hline Student work samples & 246 & $3.62(.72)$ & .60 & .36 \\
\hline $\begin{array}{l}\text { Release time to collaborate with peers } \\
\text { (within your school) }\end{array}$ & 225 & $3.40(.98)$ & .59 & .34 \\
\hline $\begin{array}{l}\text { Release time to collaborate with peers } \\
\text { (across multiple schools) }\end{array}$ & 183 & $3.23(1.21)$ & .68 & .46 \\
\hline $\begin{array}{l}\text { Board consultants (e.g., learning } \\
\text { partners, coaches) }\end{array}$ & 218 & $3.06(1.16)$ & .73 & .53 \\
\hline $\begin{array}{l}\text { Ministry resources related to focus of } \\
\text { inquiry (i.e., teaching, curriculum, } \\
\text { learning) }\end{array}$ & 242 & $2.98(1.13)$ & .60 & .36 \\
\hline $\begin{array}{l}\text { Non-ministry resources related to focus } \\
\text { of inquiry (i.e., teaching, curriculum, } \\
\text { learning) }\end{array}$ & 232 & $2.96(1.03)$ & .59 & .35 \\
\hline $\begin{array}{l}\text { Ministry resources that describe } \\
\text { collaborative inquiry (e.g., literature, } \\
\text { research, documents and videos) }\end{array}$ & 224 & $2.81(1.13)$ & .78 & .60 \\
\hline External consultants (e.g., experts) & 146 & $2.47(1.36)$ & .74 & .55 \\
\hline The School Effectiveness Framework & 232 & $2.47(1.26)$ & .72 & .52 \\
\hline $\begin{array}{l}\text { Data from common assessments (e.g., } \\
\text { EQAO) }\end{array}$ & 208 & $2.32(1.34)$ & .66 & .43 \\
\hline $\begin{array}{l}\text { Research partners (e.g., professors, } \\
\text { Ministry personnel) }\end{array}$ & 130 & $2.20(1.46)$ & .74 & .55 \\
\hline $\begin{array}{l}\text { Academic research related to inquiry } \\
\text { focus }\end{array}$ & 218 & $2.76(1.15)$ & .65 & .42 \\
\hline Non-ministry resources that describe CI & 217 & $2.73(1.18)$ & .73 & .35 \\
\hline $\begin{array}{l}\text { Resources focused on data collection } \\
\text { and analysis }\end{array}$ & 209 & $2.52(1.22)$ & .76 & .58 \\
\hline
\end{tabular}

Note. All values $>.30$ are reported. $h^{2}=$ Communality. Cronbach's alpha $=.92$ 
Table 3

Means and factor loadings for factors that inhibited CI learning

\begin{tabular}{|c|c|c|c|c|}
\hline Item & $n$ & $M(S D)$ & $\begin{array}{l}\text { Unrotated } \\
\text { Factor } \\
\text { Loading } \\
\end{array}$ & $h^{2}$ \\
\hline \multicolumn{5}{|c|}{ Factor: Constraints to CI learning (7 items) } \\
\hline $\begin{array}{l}\text { Lack of willingness of my students to } \\
\text { try new things. }\end{array}$ & 251 & $3.05(1.19)$ & .76 & .58 \\
\hline $\begin{array}{l}\text { Lack of ability to make sense of the } \\
\text { evidence I gather (i.e., analysis of } \\
\text { evidence). }\end{array}$ & 254 & $2.80(1.17)$ & .88 & .77 \\
\hline $\begin{array}{l}\text { Lack of willingness of those I am } \\
\text { working with to listen to my ideas. }\end{array}$ & 241 & $2.80(1.31)$ & .59 & .34 \\
\hline $\begin{array}{l}\text { Fear that I might be wasting } \\
\text { instructional time. }\end{array}$ & 247 & $2.78(1.32)$ & .54 & .29 \\
\hline $\begin{array}{l}\text { Lack of ability to identify what counts } \\
\text { as evidence. }\end{array}$ & 251 & $2.78(1.15)$ & .84 & .71 \\
\hline $\begin{array}{l}\text { Shifts in school focus, direction, or } \\
\text { activity that are introduced during our } \\
\text { collaborative inquiry. }\end{array}$ & 244 & $2.51(1.24)$ & .57 & .33 \\
\hline $\begin{array}{l}\text { Amount of time required of me in the } \\
\text { collaborative inquiry process and its } \\
\text { impact on my teaching time. }\end{array}$ & 247 & $2.35(1.35)$ & .50 & .25 \\
\hline
\end{tabular}

Note. All values $>.30 . h^{2}=$ Communality. Cronbach's alpha $=.89$ 
Table 4

Factors that inhibited CI learning based on focus group data

\begin{tabular}{|c|c|}
\hline Inhibiting Factor & Supporting Quotations \\
\hline $\begin{array}{l}\text { Perception of CI as } \\
\text { another 'add-on' for } \\
\text { teachers }\end{array}$ & $\begin{array}{l}\text { - "Sometimes when you formalize it, it feels like an extra job } \\
\text { instead of it being something you're interested in." } \\
\text { - "I felt it was a lot more work on us than other types of PD...I'm } \\
\text { in my first year, so it's already overwhelming." }\end{array}$ \\
\hline $\begin{array}{l}\text { Perception of CI as } \\
\text { 'inefficient' (teachers } \\
\text { having to figure out vs. } \\
\text { being taught) }\end{array}$ & $\begin{array}{l}\text { - "I feel like they have a notion in their head, an idea what they } \\
\text { want, but they're not going to tell us. We need to figure it out } \\
\text { ourselves. And it's frustrating sometimes. Just tell me what you } \\
\text { want me to do and I'll do it, you know?" } \\
\text { - "Not that we shouldn't spend money on CI, but we also should } \\
\text { spend money teaching teachers." }\end{array}$ \\
\hline $\begin{array}{l}\text { Perception that CI lacks } \\
\text { relevance to a teacher's } \\
\text { particular context }\end{array}$ & $\begin{array}{l}\text { - 'It's hard to collaborate professionally because every special } \\
\text { needs kid is different. And this teacher will say: 'This works for } \\
\text { me.' Well, it's not going to work. They may have the same } \\
\text { disability, but you're like, 'I already know that's not going to } \\
\text { work.'" } \\
\text {-You don't want to be negative, but whenever you're at a } \\
\text { professional inquiry, all you can think about is what your class } \\
\text { is going to do because that's all that really matters in the end." }\end{array}$ \\
\hline $\begin{array}{l}\text { Perception that teacher's } \\
\text { time better spent with } \\
\text { students than doing CI }\end{array}$ & $\begin{array}{l}\text { "It's been amazing, but every time we're out of the classroom, } \\
\text { we're not doing our primary function, which is to teach the } \\
\text { children and be with the children that we were hired to look out } \\
\text { for... We need to keep learning, but they definitely need to keep } \\
\text { learning." }\end{array}$ \\
\hline $\begin{array}{l}\text { Fear of exposing } \\
\text { personal teaching } \\
\text { weaknesses }\end{array}$ & $\begin{array}{l}\text { - "What if my ideas aren't good enough? What if they don't } \\
\text { match up? What if I can't be creative today?" } \\
\text { "There's always that fear...you're putting yourself out there with } \\
\text { your peers." } \\
\text { "Like I'm on a stage right now. I better say the right thing." }\end{array}$ \\
\hline $\begin{array}{l}\text { Lack of confidence in } \\
\text { out-of-touch 'experts' }\end{array}$ & $\begin{array}{l}\text { - "When they're someone that hasn't had a classroom in ten } \\
\text { years, you sit there and say: 'Okay, that's really easy for you to } \\
\text { tell me to go and do that, but let's see you do it.", }\end{array}$ \\
\hline $\begin{array}{l}\text { Lack of support } \\
\text { regarding structuring of } \\
\text { CI as a professional } \\
\text { learning process }\end{array}$ & $\begin{array}{l}\text { - "If we could have a higher order support staff or somebody from } \\
\text { the Ministry say: 'This is what we're hoping it would look like.' } \\
\text {..that would be helpful." } \\
\text { "We're thrown into these things, but we're not really guided as } \\
\text { to the way we should really go." }\end{array}$ \\
\hline $\begin{array}{l}\text { Lack of } \\
\text { confidence/familiarity } \\
\text { with new practices }\end{array}$ & $\begin{array}{l}\text { "And when they first started doing this, it was really hard } \\
\text { because we didn't know what was expected, but then the kids } \\
\text { didn't know what was expected... I was in a room once where a } \\
\text { kid started to cry because he was so frustrated because the }\end{array}$ \\
\hline
\end{tabular}




\begin{tabular}{|c|c|}
\hline & $\begin{array}{l}\text { prompt was so nebulous, and I felt that was wrong. We } \\
\text { shouldn't be making kids cry." } \\
\text { - "I think another reservation was on the parents' side. When you } \\
\text { take another approach... They had a lot of reservations and they } \\
\text { were coming forward with questions and we didn't have all the } \\
\text { answers because we were just embarking." }\end{array}$ \\
\hline $\begin{array}{l}\text { Difficulty and frustration } \\
\text { demonstrating } \\
\text { accountability of CI } \\
\text { success }\end{array}$ & $\begin{array}{l}\text { "They (the board) keep asking for the data. You know, how can } \\
\text { you assess that what you're doing is actually making a } \\
\text { difference? And that's the hard part." } \\
\text { - "My fear with it is that we had problems having hard data to } \\
\text { back up that we're doing is making an improvement in the } \\
\text { student. We know it is but we haven't got the numbers to prove } \\
\text { it and my fear is that they're going to scrap it." }\end{array}$ \\
\hline
\end{tabular}


Table 5

Means and factor loadings for perceived impact of CI on teachers

\begin{tabular}{|c|c|c|c|c|}
\hline Item & $n$ & $M(S D)$ & $\begin{array}{l}\text { Unrotated } \\
\text { Factor } \\
\text { Loading } \\
\end{array}$ & $h^{2}$ \\
\hline \multicolumn{5}{|c|}{ Factor: CI impact on teaching and learning (14 items) } \\
\hline $\begin{array}{l}\text { CI has influenced me to design instruction to } \\
\text { engage students. }\end{array}$ & 256 & $3.33(.96)$ & .75 & .65 \\
\hline $\begin{array}{l}\text { CI has influenced me to differentiate } \\
\text { instruction for my students. }\end{array}$ & 255 & $3.20(1.03)$ & .81 & .65 \\
\hline $\begin{array}{l}\text { CI has influenced me to incorporate student } \\
\text { voice, perspectives, and interests. }\end{array}$ & 253 & $3.20(1.03)$ & .76 & .58 \\
\hline $\begin{array}{l}\text { CI has influenced me to provide students with } \\
\text { descriptive feedback. }\end{array}$ & 255 & $3.16(.98)$ & .71 & .51 \\
\hline $\begin{array}{l}\text { I would engage in CI whether it was required } \\
\text { or not. }\end{array}$ & 254 & $3.15(1.00)$ & .78 & .61 \\
\hline $\begin{array}{l}\text { I would recommend CI to a colleague } \\
\text { interested in professional learning. }\end{array}$ & 256 & $3.13(1.04)$ & .80 & .65 \\
\hline $\begin{array}{l}\text { I felt personally engaged in my professional } \\
\text { learning through CI. }\end{array}$ & 256 & $3.13(1.04)$ & .84 & .70 \\
\hline $\begin{array}{l}\text { CI has influenced me to increase precision and } \\
\text { personalization in teaching and learning. }\end{array}$ & 256 & $3.13(.94)$ & .83 & .69 \\
\hline $\begin{array}{l}\text { CI has influenced me to develop learning tasks } \\
\text { based on curriculum expectations. }\end{array}$ & 256 & $3.09(1.05)$ & .75 & .56 \\
\hline $\begin{array}{l}\text { CI has influenced me to co-learn with teachers } \\
\text { in my school. }\end{array}$ & 255 & $3.08(1.10)$ & .69 & .47 \\
\hline $\begin{array}{l}\text { I can now better support my own learning and } \\
\text { teaching practice as a result of my CI. }\end{array}$ & 255 & $3.02(1.09)$ & .87 & .76 \\
\hline $\begin{array}{l}\text { CI has influenced me to co-learn with school } \\
\text { administrators. }\end{array}$ & 256 & $2.73(1.21)$ & .68 & .46 \\
\hline $\begin{array}{l}\text { I have become an instructional leader in my } \\
\text { school as a result of my engagement in } \\
\text { collaborative inquiry. }\end{array}$ & 253 & $2.20(1.44)$ & .57 & .33 \\
\hline $\begin{array}{l}\text { I was encouraged to spend time on my CI } \\
\text { professional learning. }\end{array}$ & 255 & $2.18(1.29)$ & .52 & .27 \\
\hline
\end{tabular}

Note. All values $>.30$ are reported. $h^{2}=$ Communality. Cronbach's alpha $=.94$ 
Table 6

Means and factor loadings for perceived impact of student learning

\begin{tabular}{lcccc}
\hline \multicolumn{1}{c}{ Item } & $n$ & $M(S D)$ & $\begin{array}{c}\text { Unrotated } \\
\text { Factor Loading }\end{array}$ & $h^{2}$ \\
\hline \multicolumn{1}{c}{ Factor: CI impact on student learning (9 items) } \\
\hline $\begin{array}{l}\text { Working collaboratively on shared } \\
\text { tasks }\end{array}$ & 253 & $2.96(1.01)$ & .81 & .66 \\
$\begin{array}{l}\text { Displaying increased confidence in } \\
\text { their learning }\end{array}$ & 253 & $2.83(1.05)$ & .86 & .74 \\
$\begin{array}{l}\text { Demonstrating increased engagement } \\
\text { in classroom activities }\end{array}$ & 254 & $2.78(1.11)$ & .79 & .63 \\
$\begin{array}{l}\text { Displaying enhanced understanding of } \\
\text { key concepts }\end{array}$ & 254 & $2.67(.97)$ & .79 & .62 \\
$\begin{array}{l}\text { Displaying greater inquiry skills } \\
\begin{array}{l}\text { Demonstrating improved ability to } \\
\text { make choices }\end{array}\end{array}$ & 253 & $2.58(1.09)$ & .80 & .64 \\
$\begin{array}{l}\text { Displaying increased skill at self- } \\
\text { assessing }\end{array}$ & 255 & $2.52(1.04)$ & .84 & .71 \\
$\begin{array}{l}\text { Displaying increased ability to work } \\
\text { independently }\end{array}$ & 253 & $2.40(1.07)$ & .82 & .57 \\
Having fewer absences & 254 & $1.37(1.43)$ & .51 & .67 \\
\hline
\end{tabular}

Note. $h^{2}=$ Communality. Cronbach's alpha $=.93$ 